\title{
El contrato eventual por acumulación de tareas en la Administración originado por un déficit de personal exige aludir a las concretas circunstancias extraordinarias que lo justifiquen.
}

\author{
Inmaculada Ballester Pastor \\ Catedrática de Derecho del Trabajo y de la Seguridad Social. Universidad Jaume I de \\ Castellón.
}

Resumen: El contrato eventual por circunstancias de la producción en la Administración pública exige prueba precisa y exhaustiva de las circunstancias extraordinarias concurrentes en la plantilla que provocan la no previsibilidad exigida por la norma.

Palabras clave: Contrato eventual por circunstancias de la producción. Fraude de ley. Contratos temporales. Administración pública.

\begin{abstract}
The eventual contract due to production circumstances in the Public Administration requires precise and exhaustive proof of the extraordinary circumstances concurring in the workforce that cause the non-predictability required by the norm.
\end{abstract}

Keywords: Eventual contract due to production circumstances. Fraud of law. Temporary contracts. Public administration.

\section{Introducción}

Se sustancia en el presente recurso de casación de unificación de doctrina si el último contrato eventual por circunstancias de la producción suscrito entre el recurrente, auxiliar administrativo, y el Organismo Provincial de Asistencia Económica y Fiscal de la Diputación de Sevilla tiene, o no, carácter fraudulento. Se centra el Tribunal en la falta de fortaleza de las pruebas aportadas por la empresa pública para concluir en el uso ilegal de esta figura contractual y concluye el Alto Tribunal que las circunstancias que permiten la suscripción de este contrato deben quedar especificadas de forma precisa y exhaustiva, lo que aquí no ocurre. Al no aparecer acreditada la naturaleza extraordinaria de las circunstancias que deben presentarse cuando se utilice esta modalidad contractual en las Administraciones Públicas el contrato eventual deviene indefinido, y el cese constituye despido improcedente. Señala el Tribunal que, para que la situación de déficit de personal que provoca la acumulación de tareas aparezca, debe identificarse los trabajadores concretos afectados por las circunstancias que provoca tal déficit de personal; en concreto, se requiere la alusión al número de puestos de trabajo y a las vacantes existentes y que, además, la situación que tenga lugar ponga de relieve la existencia de circunstancias extraordinarias, o imprevisibles. 


\section{Identificación de la resolución judicial comentada}

Tipo de resolución judicial: sentencia.

Órgano judicial: Tribunal Supremo. Sala de lo Social.

Número de resolución judicial y fecha: 983/2020, de 10 de noviembre.

Tipo y número recurso o procedimiento: Recurso de casación para la unificación de doctrina núm. 2323/2018.

ECLI:ES:TS:2020:3833.

Fuente: CENDOJ.

Ponente: Excmo. Sr. D. Sebastián Moralo Gallego.

Votos Particulares: carece.

\section{Problema suscitado. Hechos y antecedentes}

\section{El relato de los hechos probados}

El actor había desempeñado funciones propias de la categoría profesional de auxiliar administrativo y había sido contratado por la Diputación de Sevilla -antes de la presentación de la demanda por despido que sustancia ulteriores actuaciones- hasta en siete ocasiones. Las sucesivas vinculaciones del actor con la Diputación habían tenido lugar a través de contrataciones temporales reiteradas usando diferentes contratos temporales desde el 12 de mayo de 2008 al 21 de octubre de 2013.

Aparece en los Hechos probados, de acuerdo con la documentación obrante en los autos, la completa relación de estos contratos, haciéndose referencia exacta al modo en que cada uno de ellos fueron formalizados: la modalidad utilizada en cada caso, su duración y la causa alegada para justificar su suscripción. Según este relato, de entre estos siete contratos temporales, cinco de ellos fueron eventuales por circunstancias de la producción, el primero, segundo, cuarto, sexto y séptimo, mientras que los dos restantes, el tercero y el quinto fueron contratos de interinidad. Los contratos eventuales siempre se extendieron durante un total de seis meses exactos mientras que, en el caso de los contratos de interinidad por sustitución, los períodos de vinculación contractual fueron de un mes y medio. Además, respecto a la alegación de la causa esgrimida para justificar el uso de contratos temporales, en los contratos de interinidad por sustitución aparece la identificación de la trabajadora que es sustituida en el contrato tercero- y los nombres de los trabajadores que se encontraban de vacaciones -en el contrato quinto- para detallar el objeto que permite el uso de esta otra modalidad de contratación; por su parte, en los cinco contratos temporales eventuales por circunstancias de la producción concertados, se hace constar expresamente que la causa que justifica su suscripción es, o bien la "realización de tareas propias de la oficina" o bien la "realización de tareas propias del Servicio".

A la finalización del séptimo de estos contratos es cuando se interpone la demanda por despido. El último contrato celebrado previo a la demanda es un contrato eventual por circunstancias de la producción suscrito el 22 de abril de 2013 y concluido el 21 de octubre de 2013, y en éste aparece como causa de la contratación "la realización de las tareas propias de la oficina". El 11 de noviembre de 2013 el recurrente presenta reclamación previa frente a la entidad demandada, y sin que conste que la misma fuera expresamente resuelta por el Organismo, el día 11 de diciembre de 2013 se presenta la demanda origen de las actuaciones.Tras ello, consta referenciado igualmente en los Hechos que, desde el 9 de julio de 2014 y hasta el 8 de diciembre de 2014, el demandante fue contratado por octava vez por la Diputación de Sevilla, a través de un contrato eventual por circunstancias de la producción, contrato que se extiende durante seis meses y en el que se repite como identificación del objeto del contrato "la realización de tareas propias del servicio". 


\section{La sentencia de instancia}

La Sentencia del Juzgado de lo Social $n^{\circ} 4$ de Sevilla, de 26 de agosto de 2014, recaída en los autos $n^{\circ} 1603 / 2013$, estima en parte la demanda presentada por el trabajador frente al Organismo Provincial de Asistencia Económica y Fiscal de la Diputación de Sevilla en reclamación por despido, y declara el despido improcedente. La Sentencia entiende que los contratos se concertaron en fraude de ley, califica la relación laboral como indefinida y considera que la extinción constituye despido improcedente.

\section{La sentencia del tribunal superior de justicia}

La Diputación de Sevilla, Organismo condenado por despido, recurre en suplicación y la Sentencia de Sala de lo Social del Tribunal Superior de Justicia, con sede en Sevilla, de 5 de abril de 2018, $n^{\circ}$ de recurso 1435/2017, estima el recurso y declara la procedencia del cese del actor el día 21 de octubre de 2013, sin derecho a indemnización ni a salarios de tramitación.

Se adiciona en este pronunciamiento al Hecho probado $2^{\circ}$ los siguientes párrafos: "El anterior contrato se formaliza con el actor en cuanto integrante de la bolsa de trabajo de la categoría de auxiliar administrativo (folio 226 de las actuaciones). El $18 / 03 / 2013$ se le presenta al actor oferta con la relación de contratos indicando el orden de preferencia, señalando como contratos preferentes cuatro contratos numerados del 1 al 4 del tipo: eventual por circunstancias de la producción; categoría profesional: auxiliar administrativo; duración 6 meses; centro de trabajo: servicios centrales (folios 90 y 91 vuelto de las actuaciones). La necesidad de realizar estas contrataciones en los Servicios Centrales obedece a las necesidades de personal en los departamentos de Servicios Jurídicos según informe del Jefe de la Sección Jurídica de 15 de enero de 2013; Servicio de Gestión Tributaria, según informe del Jefe del Servicio de Gestión Tributaria de 14 de enero de 2013; y Servicio de Contabilidad según informe del Jefe del Servicio de Contabilidad de 14 de enero de 2013 (folios 84, 85 y 86 de las actuaciones), dándose sus contenidos íntegramente por reproducidos. Por resolución $n^{\circ} 168$ de 11/04/13 se resuelve contratar, mediante contrato eventual por circunstancias de la producción, por un período de seis meses, con la categoría de auxiliar administrativo, a 7 trabajadores, 4 con destino en los Servicios Centrales - entre los que se encuentra el Sr. Adriano - y 3 destinados en las OAC de Rinconada, Carmona y San Juan de Aznalfarache (folio $n^{\circ} 80$ de las actuaciones)".

Concluye este pronunciamiento que el trabajador está incluido en la bolsa de trabajo prevista en los sucesivos Convenios Colectivos del OPAEF, con la finalidad de cubrir necesidades temporales de personal por acumulación de tareas, o de interinidad, por lo que conocía perfectamente el carácter temporal de las contrataciones a las que podía acceder como integrante de esa bolsa de empleo. Se razona a continuación que los contratos eventuales no especifican adecuadamente la causa de la contratación, pero que eso no significa que el trabajador desconociera la temporalidad de su contrato. Califica esa deficiencia como una mera irregularidad formal en la consignación del objeto del contrato, descartando la existencia de fraude de ley, porque el organismo demandado ha probado la necesidad urgente de personal en diversos departamentos, y se acoge a la doctrina de la STS 7 de junio de 2011, rcud. 3028/2010, para concluir que la empleadora ha acreditado suficientemente la concurrencia de una causa de temporalidad que rompe la presunción en favor de la contratación indefinida y justifica la utilización de esa clase de contratos, en atención a la necesidad de contratar personal adicional para desempeñar adecuadamente su actividad ante el déficit de trabajadores de su plantilla ordinaria. Por ese motivo considera que no hay fraude de ley en la contratación temporal y desestima la demanda de despido al entender ajustada a derecho la extinción de su relación laboral. 


\section{El recurso de casación de unificación de doctrina}

El actor formaliza recurso de casación de unificación de doctrina y se aporta como sentencia contradictoria la del Tribunal Superior de Justicia de Andalucía, con sede en Sevilla, de 23 de noviembre de 2017 -nºc. 3579/2016-.

\section{Normativa aplicable al caso}

La normativa aplicable al conflicto son los artículos $8.2^{\circ}$, el art. $15.3^{\circ}$ y el art. 15.1.b) del Texto Refundido del Estatuto de los Trabajadores aprobado por Real Decreto legislativo 2/2015, de 23 de octubre, así como el art. $3^{\circ}$ del RD 2720/1998, de 18 de diciembre por el que se desarrolla el artículo 15 del Estatuto de los Trabajadores en materia de contratos de duración determinada, BOE de 8 de enero de 1999.

\section{Texto refundido del Estatuto de los Trabajadores}

Artículo 8. Forma del contrato.

2. Deberán constar por escrito los contratos de trabajo cuando así lo exija una disposición legal y, en todo caso, los de prácticas y para la formación y el aprendizaje, los contratos a tiempo parcial, fijos-discontinuos y de relevo y los contratos para la realización de una obra o servicio determinado; también constarán por escrito los contratos por tiempo determinado cuya duración sea superior a cuatro semanas. (...) De no observarse la exigencia de forma escrita, el contrato de trabajo se presumirá celebrado por tiempo indefinido y a jornada completa, salvo prueba en contrario que acredite su naturaleza temporal o el carácter a tiempo parcial de los servicios.

Artículo 15. Duración del contrato.

1. El contrato de trabajo podrá concertarse por tiempo indefinido o por una duración determinada. Podrán celebrarse contratos de duración determinada en los siguientes supuestos: (...) b) Cuando las circunstancias del mercado, acumulación de tareas o exceso de pedidos así lo exigieran, aun tratándose de la actividad normal de la empresa. En tales casos, los contratos podrán tener una duración máxima de seis meses, dentro de un periodo de doce meses, contados a partir del momento en que se produzcan dichas causas. Por convenio colectivo de ámbito sectorial estatal o, en su defecto, por convenio colectivo sectorial de ámbito inferior, podrá modificarse la duración máxima de estos contratos y el periodo dentro del cual se puedan realizar en atención al carácter estacional de la actividad en que dichas circunstancias se puedan producir. En tal supuesto, el periodo máximo dentro del cual se podrán realizar será de dieciocho meses, no pudiendo superar la duración del contrato las tres cuartas partes del periodo de referencia establecido ni, como máximo, doce meses. En caso de que el contrato se hubiera concertado por una duración inferior a la máxima legal o convencionalmente establecida, podrá prorrogarse mediante acuerdo de las partes, por una única vez, sin que la duración total del contrato pueda exceder de dicha duración máxima. Por convenio colectivo se podrán determinar las actividades en las que puedan contratarse trabajadores eventuales, así como fijar criterios generales relativos a la adecuada relación entre el volumen de esta modalidad contractual y la plantilla total de la empresa. (...). 3. Se presumirán por tiempo indefinido los contratos temporales celebrados en fraude de ley.

\section{Real Decreto $2720 / 1990$, de 18 de diciembre}

Artículo 3. Contrato eventual por circunstancias de la producción.

1. El contrato eventual es el que se concierta para atender exigencias circunstanciales del mercado, acumulación de tareas o exceso de pedidos, aun tratándose de la actividad normal de la empresa. Cuando el convenio colectivo que resulte de aplicación haya determinado las actividades en las que pueden contratarse trabajadores eventuales o haya fijado criterios generales relativos a la adecuada relación entre el número de contratos a realizar y la plantilla total de la empresa, se estará a lo establecido en el mismo para la utilización de esta modalidad contractual. 
2. El contrato eventual por circunstancias de la producción tendrá el siguiente régimen jurídico: a) El contrato deberá identificar con precisión y claridad la causa o la circunstancia que lo justifique y determinar la duración del mismo. b) La duración máxima de este contrato será de seis meses dentro de un período de doce meses. En atención al carácter estacional de la actividad en la que se pueden producir las circunstancias señaladas en el apartado 1 de este artículo, los convenios colectivos de ámbito sectorial estatal o, en su defecto, los convenios colectivos sectoriales de ámbito inferior podrán modificar indistintamente: $1 .{ }^{\circ}$ La duración máxima del contrato. $2 .^{\circ} \mathrm{El}$ período dentro del cual puede celebrarse. $3 .^{\circ}$ La duración máxima del contrato y el período dentro del cual puede celebrarse. En cualquier caso, los convenios colectivos señalados en el párrafo anterior no podrán establecer un período de referencia que exceda de dieciocho meses ni una duración máxima del contrato que exceda de las tres cuartas partes del período de referencia legal o convencionalmente establecido. c) El período de referencia legal o convencionalmente establecido se computará desde que se produzca la causa o circunstancia que justifique la utilización del contrato eventual. d) En caso de que el contrato eventual se concierte por un plazo inferior a la duración máxima legal o convencionalmente establecida, podrá prorrogarse mediante acuerdo de las partes, por una única vez, sin que la duración total del contrato pueda exceder de dicha duración máxima.

\section{Doctrina básica}

\section{Acerca de la contradicción entre las sentencias}

Antes de otorgar solución al conflicto el Tribunal resuelve si entre las sentencias contrastadas que son objeto del RCUD hay contradicción en los términos exigidos por el art. $219.1^{\circ}$ LRJS. A tal efecto, la Diputación de Sevilla niega la existencia de contradicción en su escrito de impugnación, mientras que el Ministerio Fiscal la admite, pero solicita la desestimación del recurso por considerar más ajustada a derecho la doctrina de la resolución recurrida.

Se invoca de contraste la Sentencia de la Sala de lo Social del Tribunal Superior de Justicia de Sevilla 23 de noviembre de 2017, n $^{\circ}$ rec. 3579/2016 y se explicita a continuación el conflicto resuelto en esta otra Sentencia.

El trabajador demandante estaba integrado en la bolsa de trabajo de la Diputación de Sevilla, y prestaba servicios como auxiliar administrativo para el mismo organismo público desde agosto de 2008. También fue contratado a través de diferentes contratos de interinidad y eventuales por circunstancias de la producción, contratos en los que se hizo constar como objeto de la contratación el de la realización de las tareas propias de la oficina. Tras presentar demanda el actor, el Juzgado de lo social había calificado el despido como improcedente, al considerar concertados en fraude de ley los contratos eventuales suscritos, por no consignarse adecuadamente la causa de la contratación. El recurso de suplicación instado por el Organismo condenado en la instancia -acogiendo la doctrina judicial contenida en la Sentencia de 10 de julio de 2013, que reitera la inserta en la Sentencia del Tribunal Supremo de 7 de junio de 2011- considera concertados en fraude de ley los contratos temporales. La Sala, en este otro pronunciamiento, aduce que el Organismo no hizo referencia expresa de los trabajadores que se encontraban en las circunstancias que la empleadora quiere hacer valer para justificar la necesidad de mano de obra adicional en tales periodos, es decir, quiénes estaban de vacaciones o estaban en situación de baja médica, en esos mismos períodos en los que se produjeron las contrataciones. Por ello, concluye la Sala que la relación laboral es indefinida, y que su extinción constituye un despido improcedente.

A la vista de lo anterior el Alto Tribunal concluye -como no podía ser de otra manera- en la identidad en los hechos y en las pretensiones en los dos asuntos en comparación, y aprecia la existencia de contradicción: las circunstancias en la contratación de ambos trabajadores son sustancialmente idénticas ya que el organismo público empleador es el mismo; el periodo temporal de referencia es muy similar; la redacción de los contratos eventuales es coincidente, y también son las 
iguales las alegaciones esgrimidas por la entidad demandada para justificar la necesidad de acudir a la contratación temporal de trabajadores para cubrir un supuesto déficit de personal de plantilla.

\section{La resolución del asunto}

Para dar solución al conflicto el Tribunal trae a colación la doctrina jurisprudencial en materia de contratos eventuales por acumulación de tareas y acude a la doctrina jdicial emanada de la STS de 26 de marzo de 2013 ( $n^{\circ}$ rec. 1415/2012), de cuyos pronunciamientos se extrae que:

\section{- $\quad$ La acumulación de tareas debe quedar bien formalizada en el contrato}

El art. 15.1.b) ET y el art. $3.2^{\circ}$ del RD 2720/1998 exigen que el contrato exprese con precisión y claridad la causa o circunstancias que justifiquen la contratación, aunque tal falta de concreción no impide que se analice la efectiva realidad de ésta, al admitirse prueba en contrario -ex. art. 8.2 ${ }^{\circ} \mathrm{ET}$-.

- La acumulación de tareas puede aparecer en la AP temporalmente cuando surja un número elevado de puestos vacantes que han de cubrirse por el procedimiento reglamentario.

Y ésta ha sido precisamente la razón -la posibilidad de permitir esta prueba de la que de deduzca la realidad de tal acumulación de tareas- el motivo por el que se ha admitido que, en el caso de las Administraciones Públicas, la insuficiencia de plantilla para atender el servicio público - es decir, un déficit de personal- pueda constituir también una causa de eventualidad que justifique la utilización de este contrato pues ésta es una causa de acumulación de tareas. Se remarca que este déficit de personal alegable podía deberse -aludiendo igualmente a la doctrina expuesta en la STS de 23 de mayo de 1994 rcud. 871/1993 y a las posteriores Sentencias del TS de 16 de mayo de 2005 rcud. 2412/2004 y de 7 de diciembre de 2011 (rcud. 935/2011)- a que exista un número de puestos de trabajo no cubiertos reglamentariamente si los titulares no acuden a prestar servicio por distintas causas.

La explicación dada al hecho de que en las Administraciones públicas aparezca la insuficiencia de plantilla que pueda actuar como un supuesto de acumulación de tareas se justifica, así, en los casos en los que el puesto de trabajo no se ha creado como tal en la relación de puestos de trabajo. Entonces cabe que aparezca esa desproporción existente entre el trabajo que se ha de realizar y el personal que se dispone; y tampoco puede usarse el contrato de interinidad por cobertura de vacante en este caso -porque las vacantes son varias, y están por determinar-.

El Tribunal razona que, como ha venido entendiendo previamente, si bien en el ámbito de la empresa privada no pueden calificarse como propios de la acumulación de tareas los casos en que el indicado desequilibrio o desproporción se debe exclusivamente a la existencia de vacantes o puestos fijos sin cubrir, ya que en la empresa privada cabe acudir a la cobertura con contratos indefinidos con igual o mayor rapidez que si tales vacantes se cubren con la contratación temporal, en cambio, en la Administración Pública la provisión de vacantes puede retrasarse porque comporta el cumplimiento de una serie de requisitos y condiciones. Eso significa que, en la Administración pública, y mientras esa cobertura de vacantes se produce, el Organismo que tiene un número elevado de puestos sin titular puede encontrarse en una situación de déficit de personal.

- La utilización del contrato eventual exige la concurrencia real de la causa esgrimida.

Pero para que aparezca la acumulación de tareas no sirve que se alegue ésta, sin más. A tal efecto,con independencia de la adecuación de que las vacaciones de la plantilla puedan servir justificar la existencia de una acumulación de tareas, no basta señalar que la concurrencia de las vacaciones de otros trabajadores de la plantilla es lo que provoca tal aparición de la acumulación de tareas -tal como se establece en la STS de 12 de junio de 2012 ( $n^{\circ}$ rec. 3375/2011)-. En tal caso, si son las vacaciones las 
que se aducen como razón para la insuficiencia de plantilla temporal se exige que se consigne la circunstancia de los permisos que dan lugar a la acumulación o los descansos de los trabajadores concretos en las que concurre tal circunstancia.

- $\quad$ En la AP solamente se acude puede esgrimir la acumulación de tareas de forma excepcional

Asimismo, trayendo a colación la Sentencia de 30 de octubre de $2019, \mathrm{n}^{\circ}$ rec. $1070 / 2017$, en relación a la contratación temporal llevada a cabo por un organismo público, se afirma que la ausencia por vacaciones no es una situación de suspensión de contrato de trabajo con derecho a reserva de plaza sino una mera interrupción ordinaria de la prestación de servicios que no genera vacante propiamente dicha. Y la utilización del contrato eventual por circunstancias de la producción se ha admitido sólo de forma particularmente excepcional dada la insuficiencia de plantilla que se puede dar en el ámbito de la administración por un desequilibrio genérico del volumen de la plantilla en las circunstancias que concuren en la AP -que precisa de procedimientos reglados- cuando no se cubran las vacantes, y ante la imposibilidad de acudir al contrato de interinidad por cobertura de vacante.

\section{Parte dispositiva}

El Tribunal estima el recurso de casación en unificación de doctrina sobre despido, casa y anula la sentencia recurrida y resuelve el debate de suplicación en el sentido de desestimar el recurso formulado por el Organismo Provincial de Asistencia Económica y Fiscal de la Diputación de Sevilla (OPAEF), confirmando la sentencia de instancia y declarando su firmeza, considerando fraudulento el contrato eventual suscrito entre la Diputación y el recurrente.

\section{Pasajes decisivos}

Concluye el Tribunal que:

Como explicamos en la precitada Sentencia de 7 de diciembre de 2011 ( $n^{\circ}$ rec 935/2011) la doctrina de esta Sala que acoge la posibilidad de utilizar la contratación eventual como mecanismo coyuntural para suplir la insuficiencia de personal en los organismos públicos, limita su alcance a las situaciones en las que se produce un manifiesto desequilibrio entre el personal disponible y la actividad que debe desarrollar el organismo, por la existencia de vacantes que no pueden ser cubiertas de modo rápido ya que deben respetarse los mecanismos legales que rigen en materia de empleo público. Por eso decimos que en estos casos concurre la situación de que el organismo público que en un momento determinado tiene un número elevado de puestos sin titular, se encuentra en una situación de déficit de personal, en la que el trabajo sobrepasa la capacidad de los empleados disponibles, situación que puede prolongarse bastante tiempo; aparece, por tanto, nítidamente el supuesto propio de la acumulación de tareas. De ahí que sea lícito el que la Administración acuda a los contratos de trabajo eventuales para remediar, en la medida de lo posible, esa situación.

Lo que no se acredita con la abstracta y genérica invocación de los periodos de vacaciones, licencias y permisos de los que disfruta el personal que configura la plantilla ordinaria del organismo público, sino que exige una prueba más precisa y exhaustiva de las concretas y especificas circunstancias concurrentes en esa plantilla, el número de puestos de trabajo y vacantes existentes en la misma, de lo que pueda deducirse la concurrencia de las circunstancias extraordinarias que justifiquen el recurso a esta modalidad de contratación temporal, pues como decimos en la mencionada STS 30/10/2019, rcud. 1070/2017, " Nada de extraordinario resulta el disfrute de los periodos de descanso y vacaciones, a los que tienen derecho todos los trabajadores de la empresa".

Por tanto, al no aparecer acreditada ninguna causa extraordinaria de esta índole no puede considerarse probada la concurrencia de estas singulares razones que pudieren 
justificar los contratos eventuales concertados con el demandante, que deben considerarse celebrados en fraude de ley.

\section{Comentario}

Si no nos detenemos en el detalle de este pronunciamiento -contenido muy sintéticamente en los dos últimos párrafos de la Sentencia arriba referenciadosparecería que estamos ante una Sentencia dedicada a reiterar previa doctrina del Alto Tribunal, pero no es así, porque se pretende avanzar queriendo restringir el uso del contrato eventual por acumulación de tareas a casos muy limitados, y lo hace buscando la realidad de la causa que justifica la acumulación en los datos precisos que identifican personas, trabajadores y puestos de trabajo afectados por ella. El objeto del RCUD es concluir si el contrato eventual concertado entre el recurrente y la Diputación es, o no, fraudulento, y se concluye que sí, porque no se ha detallado la realidad de la circunstancia alegada que justificaría la contratación. Pero, además, se añade a lo anterior que: pues como decimos en la mencionada STS 30/10/2019, rcud. 1070/2017, " Nada de extraordinario resulta el disfrute de los periodos de descanso y vacaciones, a los que tienen derecho todos los trabajadores de la empresa".

¿Qué se quiere decir con ello?, ¿cambia su doctrina el Alto Tribunal acerca de que el déficit de personal justifica el uso del eventual en el caso de la aparición de licencias retribuidas, o de vacaciones de la plantilla -una doctrina que ha resultado ser altamente polémica-? ¿Lo hace solamente en la Administración Pública?

Entendemos que no, no se rechaza el uso del eventual para cubrir déficit de personal -el que aparece con ocasión de vacaciones, licencias, es decir, puestos que no están vacantes y se van a cubrir con los titulares de la plaza-. No obstante, sí se percibe una voluntad de insistir por parte del Alto Tribunal en la necesidad de que este déficit de personal -cuando se alegue y demuestre claramente- realmente aparezca, lo que solamente puede ocurrir en un número limitado de casos, y de forma restrictiva, pues, tal como se añade, debe limitarse a reducidos casos, donde esta circunstancia deba ser puntual, extraordinaria, o no previsible y ello debe acreditarse por la empleadora. El Tribunal hace, así, una llamada a la doctrina contenida en la STS de 30 de octubre de 2019 -Sentencia en la que el conflicto planteado tiene como base un contrato de interinidad por sustitución- y aplica ésta a este conflicto, lo que es altamente trascendente.

Repasemos, por tanto, las afirmaciones contenidas en la Sentencia y, a resultas de ello, cuáles serían los requisitos o las condiciones que han de concurrir para que un contrato eventual por acumulación de tareas, basado en un déficit de personal producido por razones que concurren en la empresa -licencias o vacaciones del personal- pueda quedar válidamente suscrito.

$1^{\circ}$ requisito. La causa o el objeto de la contratación ha de quedar consignada adecuadamente y formalizada como tal en el documento escrito. Pero, si no se hace así, según prevé la norma (art. 8.2 $2^{\circ}$ ET y art. $15.3^{\circ} \mathrm{ET}$ ) puede aportarse prueba en contrario que acredite la concurrencia de ésta. En cualquier caso, si la prueba no se aporta, el contrato deviene en indefinido. Esta es la doctrina que dimana de la STS de 7 de junio de 2011 -RJ 2011, 5326-. Y es la idea que subyace las dos Sentencias que dan pie al RCUD en las que se exige que el contrato temporal se formalice efectivamente, no siendo éste el objeto de la controversia.

$2^{\circ}$ requisito. La utilización del contrato eventual exige la concurrencia de tal causa, no pudiendo servir la mera referencia de su simple coincidencia con el disfrute de las licencias, o con las vacaciones de otros trabajadores de la plantilla, de forma que se demanda algo más. Esta es la conclusión a la que llega la STSJ que se aporta como contraste en el RCUD, la STSJ de Andalucía, Sevilla, de 23 de noviembre de 2017, JUR 2018, 12374, pronunciamiento que alude a la doctrina contenida en la STS (Sala de lo Social) de 10 de julio de 2013 (RJ 2013, 6575), en la que se dice que: la cláusula del contrato de trabajo del actor ha expresado la causa o causas de la suplencia, pero no ha especificado con la precisión requerida en la normativa aplicable el nombre del 
trabajador o trabajadores sustituidos (...) tal especificación podría resultar muy difícil e imposible respecto de algunas de las circunstancias genéricas aportadas pero (la empresa) si podía y debía haber especificado...Y esta misma es la doctrina que aparece en la STS de 26 de marzo de 2013 (RJ 2013/3680) que es la que el Tribunal usa para apoyar casi completamente su Fundamentación. Por ello la acumulación de tareas exige una prueba más precisa y exhaustiva de las concretas y específicas circunstancias concurrentes en esa plantilla, el número de puestos de trabajo y las vacantes existentes en la misma, de lo que pueda deducirse la concurrencia de tales circunstancias extraordinarias.

$3^{\circ}$ requisito. Una vez tenemos todos los detalles de los puestos de trabajo que están por cubrir queda por efectuar la última operación, comprobar si, de la realidad de los datos manejados, se puede deducir que concurren circunstancias que tengan la consideración de extraordinarias, pues no siempre que esta identificación simplemente se produzca ello determinará que concurren las circunstancias extraordinarias que justifican la contratación eventual. Eso es lo que se hace, precisamente, en la STS (Sala de lo Social) de 30 de octubre de 2019 (RJ 2019, 4828) - a la que se remite la STS comentada- en la que se suscriben un total de 242 contratos de interinidad por sustitución entre la trabajadora, limpiadora, y el Hospital en el que ésta trabaja. En todos y cada uno de estos contratos la entidad pública había identificado la persona a quien ésta sustituía, por asuntos propios, por días de convenio, por recuperación horaria, por vacaciones, etc, y en este pronunciamiento se concluye que la contratación temporal es fraudulenta pues ésta solamente es posible si se acredita la concurrencia de elementos para que aparezcan circunstancias no previsibles. A la vista de estos 242 suscritos por la trabajadora con la Administración se concluye que la empresa es plenamente conocedora de que la plantilla con la que cuenta disfruta de vacaciones y descansos con la regularidad propia del volumen de actividad habitual, por consiguiente, tales ausencias se producen dentro del normal desarrollo del contrato de trabajo y forman parte de la previsión organizativa que corresponde llevar a cabo al empleador, alejándose de la excepcionalidad que el contrato eventual viene a solventar, $\mathrm{y}$, concluye este pronunciamiento .... nada de extraordinario resulta el disfrute de los períodos de descanso y vacaciones, a los que tienen derecho todos los trabajadores de la empresa.

Por tanto, en suma, el déficit de la plantilla solamente podría justificar el uso del contrato eventual cuando aparezca de forma puntual, imprevisible y/o sobrevenida ese déficit de la plantilla, y no cuando este déficit sea un problema que late en la plantilla en general, porque no cuenta con la dimensión que debería -supuesto éste que es el que aqueja a nuestra Administración pública, como es bien sabido-. Y es la Administración quien debe dar más datos acerca de la ello, lo cual supone, en la práctica, restringir y acotar más su uso.

\section{Apunte final}

Queda todavía muy lejos el cumplir con el objetivo plasmado en la cláusula $5^{\circ}$ de la Directiva 1999/70/CE del Consejo, de 28 de junio de 1999, relativa al Acuerdo Marco de la CES, la UNICE y la CEEP sobre el trabajo de duración determinada. La Administración sigue recurriendo a la contratación eventual por circunstancias de la producción y, cuando lo hace para cubrir un déficit de plantilla que resulta ser estructural y no puntual se desdibujan las medidas destinadas a evitar la utilización abusiva de la utilización sucesiva de relaciones de duración determinada. La norma debe hacerse cumplir y para ello debe indagarse en el funcionamiento correcto y en la dimensión ideal de la plantilla. Igual que se hace con la búsqueda del contrato temporal fraudulento en la cadena de los contratos suscritos con una sola persona debe controlarse toda la plantilla de la Administración, y es la empresa pública la que debe hacerse cargo de esa demostración si quiere eliminar el fraude en la contratación. Estamos, pues, ante un avance en el control del uso abusivo de esta modalidad contractual, todo paso hace camino. 